www.jmscr.igmpublication.org

Index Copernicus Value: 79.54

ISSN (e)-2347-176x ISSN (p) 2455-0450

crossrefDOI: https://dx.doi.org/10.18535/jmscr/v7i3.97

\title{
Columnar Cell Lesions in patients with Invasive Breast Carcinoma and their correlation with clinico-pathological characteristics.
}

\author{
Authors \\ Dr Roopal Rathi, MBBS, MD*, Dr Nita Khurana, MBBS, MD, \\ Dr T. Singh, MBBS, MD, FRCP, Dr P.N. Agrawal, MBBS, MS
}

Department of Pathology and Department of Surgery, Maulana Azad Medical College and Associated Lok

Nayak Hospital, New Delhi- 110002

*Corresponding Author

Roopal Rathi

Address: 186, Manavta Nagar, Kanadia Road, Indore- 452016

Phone numbers: 08447631119, Email: roopalmgm@gmail.com

\begin{abstract}
Columnar cell lesions (CCL) are hypothesised as earliest pre invasive lesions of Breast cancer due to similarities with DCIS and Carcinoma. Many of the morphologic and genetic studies describe their association with low-grade carcinomas. Prevalence of CCL was studied in 37 Indian patients with Invasive Breast Carcinoma who did not receive neo-adjuvant chemotherapy with aid of 4 additional sections within $2 \mathrm{~cm}$ of tumor edges were taken. CCL's were identified and classified in 26 cases (70.27\%). Columnar Cell Change (CCC) were present in 13, Columnar Cell Hyperplasia (CCH) in 11, CCC with atypia in 9, CCH with atypia and $\mathrm{CCH}$ with atypia and complex architecture were present in 2cases each. Distribution was extensive in $8.1 \%$, multifocal $32.4 \%$, and focal $29.7 \%$ cases. These findings were correlated with various known parameters assessed by chi-square and fischer's exact test. These included patient age, menopausal status tumor size lymph node status, tumor grade, necrosis, emboli, adipose tissue infiltration, tumor lymphocytic infiltrate, margins, stage. It was concluded that CCL's do-not correlate with any clinicopathologic parameter and thus, are not helpful in determining prognosis of patients.
\end{abstract}

\section{Introduction}

First described in 1945 as 'Blunt duct adenosis', and then in 1961 as 'Columnar metaplasia'; Columnar cell lesions (CCL) of breast are long known entities characterized by enlargement of terminal duct lobular units (TDLU) with or without hyperplasia and /or atypia. In 1970 Azzopardi was the first to describe them in relation to cancer giving the term 'Clinging Carcinoma'. ${ }^{3}$
Most accepted terminology by all is classification by Schnitt and Vincent Salmon ${ }^{4}$ who categorized these entities into Columnar cell Change (CCC), columnar cell Hyperplasia $(\mathrm{CCH})$ and Flat epithelial Atypia (FEA) which includes both CCC with atypia and $\mathrm{CCH}$ with atypia.

Biopsies performed secondary to micro calcifications discovered on Mammographic screening are frequently associated with these lesions and thus, have raised curiosity regarding 
CCL's. Various studies conducted have their similarities to DCIS and other invasive entities. ${ }^{2-17}$ This has led to the hypothesis that CCL may be the earliest morphological pre-invasive lesions of low-grade Breast cancer. The few longitudinal studies ${ }^{23-26}$ conducted however, are inconclusive. This study is undertaken with aim to bridge the gap in knowledge about Indian patients with invasive breast carcinoma. Also an attempt has been made to find a correlation with various prognostic parameters

\section{Subjects and Methods}

The present study included 37 cases of Breast Carcinoma who underwent mastectomy or lumpectomy without any previous chemotherapy. An informed and written consent was obtained from all the patients followed by a detailed Clinical history and examination.

The tissue received as mastectomy/lumpectomy was routinely processed for histopathological analysis. Additional 4 sections from within $2 \mathrm{~cm}$ of all advancing edges of tumour were also taken. The morphology was studied in detail and histological typing done with detailed analysis of other histological characteristics.

The tissue was explored for CCL's and they were described according to extent, patterns, cytologic features, calcification with classification according to extended Schnitt and Vincent Salmon classification ${ }^{5}$ into Columnar Cell Lesions (CCC), Columnar Cell Hyperplasia (CCH), CCC with atypia, $\mathrm{CCH}$ with atypia, $\mathrm{CCH}$ with complex architecture and $\mathrm{CCH}$ with atypia with complex architecture.. Their location was noted and they were analysed semi quantitatively as Focal (only rare microscopic foci), Multifocal (multiple lobules or ducts in less than $50 \%$ of sections) and Extensive (multiple lobules or ducts in more than $50 \%$ of sections). ${ }^{9}$

Correlation between various prognostic parameters of breast cancer (including patient age, menopausal status tumor size lymph node status, tumor grade, necrosis, emboli, adipose tissue infiltration, tumor lymphocytic infiltrate, margins, stage) and CCL's was analysed using Chi square and Fischer's exact test to look for any significance.

\section{Results}

Study group patients had 50 years of mean age at presentation and $40.5 \%$ (15) patients under the age of 40 years. The premenopausal women formed $43.2 \%$ of the total cases. 36 cases were of IDC $(97.3 \%)$ and one patient had colloid carcinoma. Most common presenting complaint remained lump in breast in 35 (97.3\%) patients. Lymph node metastasis was observed in 22 (59.5\%) of the cases. Most of the cases presented in stage II (22- $73 \%$ ), followed by stage III (14$21.6 \%$ ) and one at Stage IV. 7 cases showed IDC NOS grade I while 19 and 10 showed Grade II and Grade III, respectively. Infiltrative margin was observed in 30 cases, while necrosis in $62.2 \%$, calcification in $24.3 \%$, inflammatory infiltrate in $91.9 \%$ and Adipose tissue infiltrate (ATI) in $81.1 \%$ of cases. ER was expressed in $40.54 \%$ (15) cases and PR was expressed in $32.43 \%$ (12) of cases. Her2 neu expression was observed in 16 cases $(43.24 \%)$.

A large no., 26/37 cases (70.27\%) showed presence of CCL's. The negative cases included Colloid Carcinoma. Different types of CCL's coexisted in 11 cases representing the spectrum of changes. Most frequent were CCC (14/37) followed by $\mathrm{CCH}$ (11/37). 9 cases (24.3\%) showed $\mathrm{CCC}$ with atypia, $\mathrm{CCH}$ with atypia and $\mathrm{CCH}$ with atypia with complex architecture were seen in 2 cases each (Figure 1).

Comparison of various clinco-pathological parameters in cases with and without CCL's is listed in Table1. 
Table 1: Correlation of Presence of CCL with Clinicopathological Profile

\begin{tabular}{|c|c|c|c|c|}
\hline & & $\mathrm{CCL}+$ & CCL- & p VALUE \\
\hline \multirow{2}{*}{ Age Group } & $<40$ & 10 & 5 & \multirow[t]{2}{*}{0.69} \\
\hline & $>40$ & 16 & 6 & \\
\hline \multirow[t]{2}{*}{ Laterality } & RIGHT & 10 & 9 & \multirow[t]{2}{*}{0.018 (FISCHER'S) } \\
\hline & LEFT & 16 & 2 & \\
\hline \multirow[t]{2}{*}{ Menopausal Status } & PRE & 11 & 5 & \multirow[t]{2}{*}{0.86} \\
\hline & POST & 15 & 6 & \\
\hline \multirow[t]{2}{*}{ Tumor Size } & $\leq 5 \mathrm{~cm}$ & 24 & 8 & \multirow{2}{*}{0.235} \\
\hline & $>5 \mathrm{~cm}$ & 3 & 3 & \\
\hline \multirow[t]{2}{*}{ Lymph Node } & NEG & 11 & 4 & \multirow[t]{2}{*}{0.736} \\
\hline & POS & 15 & 7 & \\
\hline \multirow[t]{3}{*}{ Tumor Grade } & 1 & 6 & 1 & \multirow[t]{3}{*}{ 0.251(FISCHER'S) } \\
\hline & 2 & 15 & 4 & \\
\hline & 3 & 5 & 5 & \\
\hline \multirow{2}{*}{ Tumor Necrosis } & PRESENT & 16 & 11 & \multirow[t]{2}{*}{0.967} \\
\hline & ABSENT & 6 & 4 & \\
\hline \multirow[t]{2}{*}{ Tumor Emboli } & PRESENT & 17 & 8 & \multirow[t]{2}{*}{0.776} \\
\hline & ABSENT & 8 & 3 & \\
\hline \multirow[t]{2}{*}{ Pathological Stage } & I/II & 14 & 8 & \multirow[t]{2}{*}{0.284} \\
\hline & III/IV & 12 & 3 & \\
\hline
\end{tabular}

*CCL+ refers cases of invasive carcinoma with Columnar cell lesions

**CCL- refers cases of invasive carcinoma without Columnar cell lesions
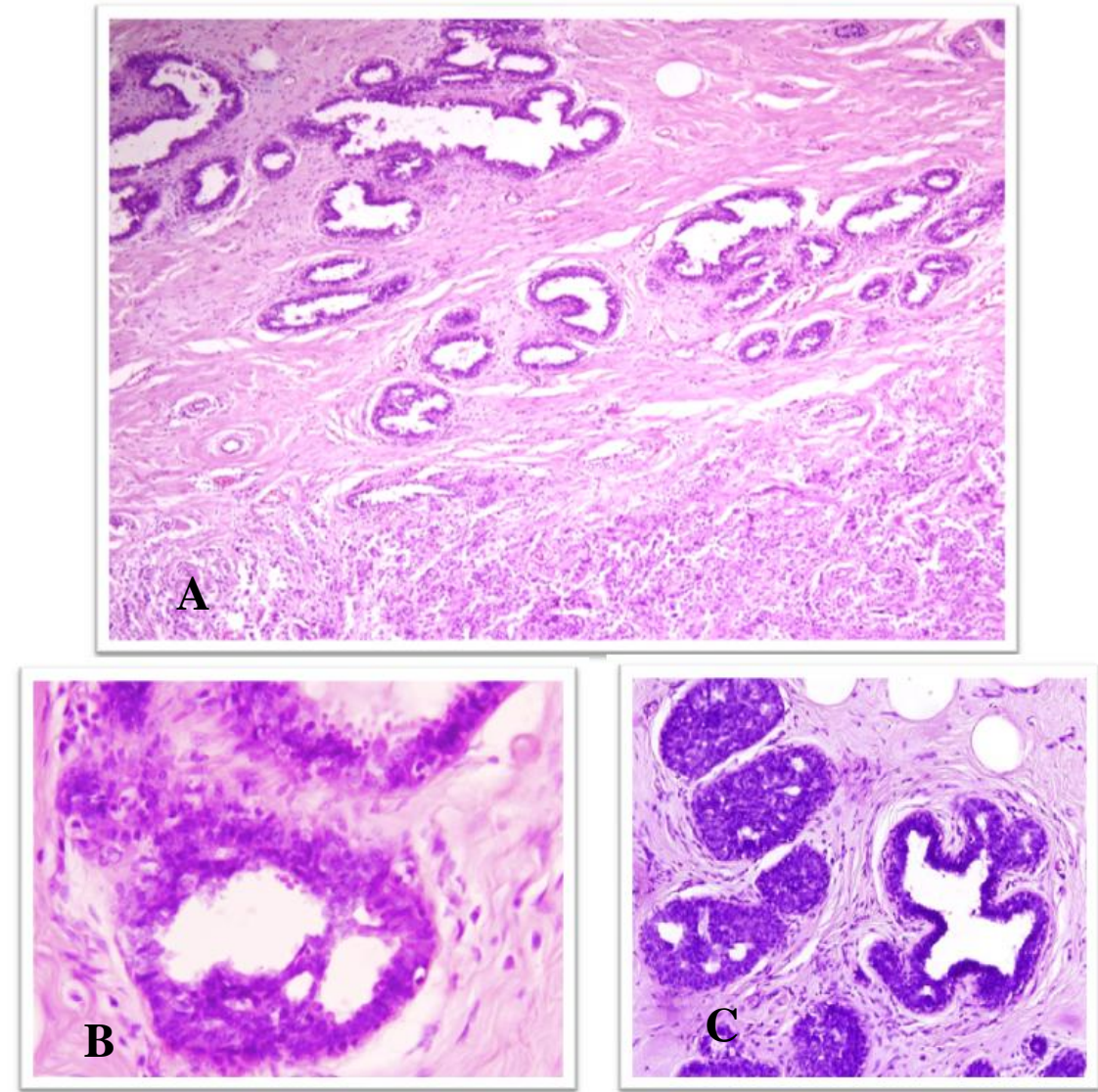

Fig. 1: A Columnar Cell Hyperplasia adjacent to IDC (HE stain, 40x). Multiple dialated ducts near the tumor lined by single to multiple layer of nuclei without atypia and oriented perpendicularly. B Complex architecture (HE stain, 400x): $\mathrm{CCH}$ with atypia showing rigid bridges and micropapillae There is high degree of nuclear pleomorphism. Apical snouts are still preserved. C.CCC with atypia near Tumor (HE stain, 100X) single layer of atypical cells lining the dialated duct near tumor. Myoepithelial layer is intact. 


\section{Discussion}

Although various studies have helped to characterize Columnar cell lesions, still certain aspects remain untouched, like detailed analysis of correlation with various clinic-pathological parameters, as done in our study.

We observed presence of different types of CCL's in $70.27 \%$.(26) of our cases. The only case of Colloid Carcinoma included in the study did not show any CCL's; similar to Leibel et al and Abdel Fateh et al. ${ }^{5,6}$ However, H.Seema and $\mathrm{T}$ Rajlakshmi found them in only $30.2 \%$ of IDC $^{7}$ and Goldstein and O' Malley reported them as cancerisation of small ectatic ducts in $6.23 \%$ ${ }^{8}$ Additional sections taken within $2 \mathrm{~cm}$ of tumor increased our yield of cases by $18.9 \%$.

Similar to findings of Demiralay et al, more than one type of CCL's were found in 11 cases with $\mathrm{CCC}$ and $\mathrm{CCH}$ being most frequent. ${ }^{9}$ However, Abdel Fatah et al found $\mathrm{CCH}$ with atypia as most commonly followed by CCC. ${ }^{6}$ This is contrasting, as CCL's with atypia are considered to be precursors of carcinoma, and not CCL's without atypia.

Similar to findings of Fraser et al, Senneta et al and Lavoue' et al, age, menopausal status and other risk factors showed no significant difference on comparison between CCL and non CCL cases and also CCL with atypia and without atypia cases. ${ }^{10-12}$

Maximum cases showing CCL's were Grade II $(57.7 \%)$ both with and without atypia group while that without CCL's had more cases in Grade III. This is similar to findings of Demiralay et al, who found almost equal occurrence in cases of Grade I and Grade II of both CCL with and without atypia, although in most of the cases with Grade III tumor, CCL with atypia were present. ${ }^{9}$ On the contrary, Goldstein O' Malley found them only in Low Grade Carcinoma (Grade I and Tubular). ${ }^{8}$ Also, the Genetic studies indicate their association with Low Grade carcinomas. ${ }^{13-}$ ${ }^{15}$ However, 50\% of our cases of Grade III carcinomas showed presence of CCL's which is consistent with Demiralay et al who found them in $86 \% .^{9}$ Distribution of both, cases with and without CCL were maximum in Stage 2 followed by Stage 3. Nodal status was not affected by the presence or absence of CCL or with type of CCL, neither was presence of tumor necrosis. Thus, there is no association of CCL's with low-grade carcinomas. High incidence of CCL's in Breast carcinoma, as found in this study is suggestive of the precursor role of these lesions. Though, a definitive role of only those showing atypia is suggested by genetic studies $^{13-15}$, longitudinal studies conducted by Boulus et $\mathrm{al}^{16}$ and Aroner et $\mathrm{al}^{17}$ showed no significant difference among risk of carcinoma between cases of CCL's with or without atypia. Thus, they may be included among the nonobligate precursors of Cancer.

\section{Summary}

High Incidence of CCL's in Breast carcinoma is suggestive of precursor role in Invasive Breast carcinoma.

None of the clinico-pathological parameter correlates with presence or absence of CCL's.

Presence of CCLs is associated with all grades of carcinoma, not only low-grade Carcinoma as described in other studies.

There is no prognostic implication of finding CCL's in cases of Invasive carcinoma.

\section{References}

1. Foote FW, Stewart FW. Comparative studies of cancerous versus noncancerous breasts. Ann. Surg. 1945; 121: 6-53.

2. Feeley L, Quinn CM. Review Columnar Cell Lesions of Breast. Histopathology 2008; 52:11-9.

3. Azzopardi. JG Problems in Breast Pathology. London, Philadelphia: WB Saunders; 1979.p.192-239

4. Schnitt SJ. Review: the diagnosis and management of Pre-invasive breast disease, Flat Epithelial AtypiaClassification, Pathologic features and 
clinical significance. Breast Cancer Res 2003; 5: 263-8

5. Leibel S, Regitnig P, Moinfar F. Flat epithelial Atypia (DIN1a, atypical columnar change): an underdiagnosed entity very frequently coexisting with lobular neoplasia. Histopathol 2007; 50: 859-65.

6. Abdel-Fatah TMA, Powe DG, Hodi Z, Lee AHS, Reis-Filho JS, EllisIO. High frequency of coexistence of columnar cell lesions, lobular neoplasia, and low grade ductal carcinoma in situ with invasive tubular carcinoma and invasive lobular carcinoma. Am. J. Surg. Pathol. 2007; 31: 417-26.

7. Seema HS, Rajalakshmi T. Columnar cell lesions of Breast- significant or not? Indian J Surg 2007; 69:191-3.

8. Goldstein N.s., O'Malley B. Cancerization of Small Ectatic Ducts of the Breast by Ductal Carcinoma in Situ Cells with Apocrine Snouts: A Lesion associated with Tubular Carcinoma. Am J of ClinPathol 1997; 5: 561-5.

9. Demiralay E, Demirham B, Kocbiyik A, Sar A, Altaca G. Immunohistochemical and morphologic findings in columnar cell lesions of breast. Indian $\mathbf{J}$ of Pathol and Microbiology 2011; 54:335-7.

10. Fraser JL, Raza S, Chorny K, Connolly JL, Schnitt SJ. Columnar alteration with prominent apical snouts and secretions: a spectrum of changes frequently present in breast biopsies performed for microcalcifications. Am J SurgPathol1998; 22:1521-7

11. Senetta R, Campanino PP, Mariscotti G, Garberoglio S, Daniele L, Pennecchi F et al. Columnar cell lesions associated with breast calcifications on vacuum-assisted core biopsies: clinical, radiographic, and histological correlations. Modern Pathol 2009; 22: 762-9.

12. Lavoue' V, Roger CM, Poilblanc M, Proust N, Monghal-Verge C, Sagan C. Pure flat epithelial atypia (DIN 1a) on core needle biopsy: study of 60 biopsies with follow-up surgical excision. Breast Cancer Res Treat 2011; 125:121-6.

13. Moinfar F, Man YG, Bratthauer GL, Ratschek M, TavassoliFA.Genetic abnormalities in mammary ductal intraepithelial neoplasia-flat type ('clinging ductal carcinoma in situ'): a simulator of normal mammary epithelium. Cancer 2000; 88: 2072-208.

14. Dabbs DJ, Carter G, Fudge M, Peng Y, Swalsky P, Finkelstein S. Molecular alterations in columnar cell lesions of the breast. Mod Pathol 2006; 19:344-9.

15. Aulmann S, Elsawaf Z, Penzel R, Schirmacher P, Sinn HP. Invasive Tubular Carcinoma of the breast frequently is clonally related to Flat epithelial Atypia and low grade Ductal carcinoma in situ. Am J SurgPathol 2009; 33: 1646-53.

16. Boulos FI, Dupont WD, Simpson JF, Schuyler PA, Sanders ME, Freudenthal ME, Page DL. Histologic associations and long-term cancer risk in columnar cell lesions of the breast: a retrospective cohort and a nested case-control study. Cancer 2008; 113:2415-21

17. Aroner SA, Collins LC, Schnitt SJ, Connolly JL, Colditz GA, Tamimi RM. Columnar cell lesions and subsequent breast cancer risk: a nested case-control study. Breast Cancer Research 2010; 12:R61. 